\title{
SHRINKAGE REDUCTION AND CRACK PREVENTION OF ALKALI-ACTIVATED PHOSPHOROUS SLAG CEMENT
}

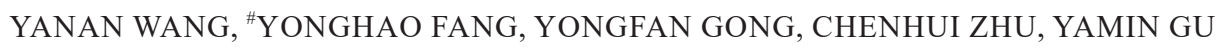 \\ College of Mechanics and Materials, Hohai University, Nanjing 210098, P.R. China \\ \#E-mail: fangyh@hhu.edu.cn
}

Submitted September 20, 2015; accepted February 1, 2016

\begin{abstract}
Keywords: Alkali-activated cement, Phosphorous slag, Shrinkage, Cracking, Expansive agent, Polypropylene fiber
The effects of fly ash, calcium oxide and polypropylene fiber on the physical and mechanical properties, shrinkage and cracking behaviors of alkali-activated phosphorous slag cement $(A A-P S-C)$ were studied. The results show that replacing $10-15 \%$ phosphorous slag by fly ash and adding calcium oxide as an expansive agent reduce the shrinkage of $A A-P S-C$. Fly ash will increase the flexural strength, although the compressive strength will be slightly decreased, while the calcium oxide expansive agent coated with aluminum stearate will slightly shorten the setting time and reduce the strength. Adding polypropylene fiber can greatly increase the crack-resistance of $A A-P S-C$.
\end{abstract}

\section{INTRODUCTION}

Phosphorous slag is a waste by-product from yellow phosphor production. Research results have proved that it is possible to prepare alkali-activated phosphorous slag cement (AA-PS-C) by mixing phosphorous slag powder, or mixture of that with fly ash, with water glass [1-3]. These cements exhibit high strength, and their corrosion and frost resistances are significantly better than those of Portland cement. Unfortunately, pastes prepared with AA-PS-C exhibit high shrinkage, much higher than pastes prepared with ordinary Portland cement. As a consequence, cracking of the cement paste and concrete occurs just as in alkali-activated blast furnace slag cement [4-8]. Although expansive agents and shrinkage-reducing admixtures have been efficiently used in ordinary Portland cement concrete [9-11], they are not effective for AA-PS-C. Either they are inefficient or have severe adverse effects on the mechanical properties [12].

To reduce the shrinkage of AA-PS-C, the effects of fly ash partly replacing phosphorous slag, and addition of calcium oxide expansive agent (CE) on the shrinkage, setting time and strength of AA-PS-C were studied in the present work. Polypropylene fiber has been widely and efficiently used in cracking prevention of ordinary Portland cement concrete [13-16]. Therefore, in the present work, the cracking prevention effect of polypropylene fiber on AA-PS-C was studied as well.

\section{EXPERIMENTAL}

\section{Materials}

Granulated phosphorous slag (PS) with Blaine specific surface area (SSA) of $483 \mathrm{~m}^{2} \cdot \mathrm{kg}^{-1}$ was supplied by Yunnan Phosphorus Group Co., Ltd, and fly ash (FA) with SSA of $462 \mathrm{~m}^{2} \cdot \mathrm{kg}^{-1}$ was supplied by Nanjing Huaneng Power Plant, respectively. The chemical compositions of PS and FA as analyzed by Jiangsu Test and Analysis Center with chemical methods according to JC/T 10882008 [17] and GB/T 176-2008 [18], respectively, are shown in Table 1 . The $\mathrm{SiO}_{2} / \mathrm{Na}_{2} \mathrm{O}$ module of the water glass used as the activator was 1.4. Calcium oxide expansive agent (CE) was prepared by firing analytical reagent $\mathrm{CaCO}_{3}$ at $1450^{\circ} \mathrm{C}$ for 2 hours, followed by mixing with 0.5 wt. $\%$ aluminum stearate at $200^{\circ} \mathrm{C}$, so that the aluminum stearate melted and coated the surface of the $\mathrm{CaO}$ particles. Ordinary Portland cement P.II 42.5 (PII), conforming to the Chinese standard GB 175-2007 [19], were used as the reference. ISO standard

Table 1. Chemical compositions of phosphorous slag and fly ash (wt. \%).

\begin{tabular}{lcccccccc}
\hline Material & $\mathrm{SiO}_{2}$ & $\mathrm{Al}_{2} \mathrm{O}_{3}$ & $\mathrm{Fe}_{2} \mathrm{O}_{3}$ & $\mathrm{CaO}$ & $\mathrm{MgO}$ & $\mathrm{P}_{2} \mathrm{O}_{5}$ & $\mathrm{SO}_{3}$ & $\mathrm{IL}^{*}$ \\
\hline PS & 41.23 & 4.40 & 4.87 & 44.06 & 0.27 & 1.44 & - & 1.70 \\
FA & 49.76 & 32.88 & 4.04 & 3.67 & 1.09 & - & 0.63 & 2.32 \\
\hline
\end{tabular}

* Mass loss after being ignited at $950^{\circ} \mathrm{C}$ for $20 \mathrm{~min}$. 
sand was used for preparing mortar specimens. A type of polypropylene fiber with diameter and length $28 \mu \mathrm{m}$ and $12 \mathrm{~mm}$, respectively, was used to reduce cracking.

\section{Experimental methods}

\section{Setting time and strength test}

AA-PS-C cements with the raw material mix proportions shown in Table 2 were prepared. The content of water glass equivalent to $\mathrm{Na}_{2} \mathrm{O}$ for all the cements was fixed at 6 wt. $\%$ of the sum of PS, FA and CE. The setting time of the cement pastes were tested according to GB/T 1346-2001 [20].

The flexural and compressive strengths were tested according to GB/T17671-1999 [21]. Mortar specimens of $40 \times 40 \times 160 \mathrm{~mm}$ were prepared with a sand to AA-PS-C ratio of 3.0 and a water (including the water contained in the water glass) to AA-PS-C ratio of 0.5 . The specimens were cured in the mould at $20( \pm 1)^{\circ} \mathrm{C}$ and relative humidity $(\mathrm{RH})>90 \%$ for 24 hours, and cured in water of $20( \pm 1)^{\circ} \mathrm{C}$ after demoulding. Flexural and compressive strengths were tested at the age of 3 days and 28 days by a TYE-10C flexural and compressive testing machine for cement mortar manufactured by China Wuxi Jianyi Instrument and Machinery Co., Ltd. Three specimens were tested each cement at each age according to the standard.

Table 2. Mix proportions (in weight) of AA-PS-C.

\begin{tabular}{lccc}
\hline Cement & PS & FA & CE \\
\hline PF0 & 100 & 0 & 0 \\
PF1 & 90 & 10 & 0 \\
PF2 & 85 & 15 & 0 \\
PF3 & 80 & 20 & 0 \\
PF4 & 70 & 30 & 0 \\
PFC1 & 85 & 15 & 1 \\
PFC2 & 85 & 15 & 2 \\
PFC3 & 85 & 15 & 3 \\
PFC4 & 85 & 15 & 4 \\
\hline
\end{tabular}

Table 3. Physical and mechanical properties of AA-PS-C.

\begin{tabular}{|c|c|c|c|c|c|c|c|}
\hline \multirow[t]{2}{*}{ No. } & \multirow{2}{*}{$\begin{array}{l}\text { Water requirement } \\
\qquad(\%)\end{array}$} & \multicolumn{2}{|c|}{ Setting time (min) } & \multicolumn{2}{|c|}{ Flexural strength $(\mathrm{MPa})$} & \multicolumn{2}{|c|}{ Compressive strength $(\mathrm{MPa}$} \\
\hline & & initial & $\overline{\text { final }}$ & 3 day & 28 day & 3 day & 28 ay \\
\hline PF0 & 26.4 & 50 & 75 & 4.7 & 6.6 & 30.9 & 98.8 \\
\hline PF1 & 26.0 & 55 & 78 & 4.0 & 7.0 & 27.8 & 73.8 \\
\hline PF2 & 25.8 & 58 & 80 & 4.4 & 9.8 & 25.8 & 78.1 \\
\hline PF3 & 25.6 & 62 & 85 & 3.8 & 8.7 & 25.5 & 65.9 \\
\hline PF4 & 25.4 & 72 & 94 & 3.1 & 5.9 & 17.2 & 51.3 \\
\hline PFC1 & 26.6 & 55 & 72 & 4.3 & 9.5 & 25.6 & 76.5 \\
\hline $\mathrm{PFC} 2$ & 26.8 & 48 & 64 & 4.5 & 9.4 & 25.8 & 75.9 \\
\hline $\mathrm{PFC} 3$ & 27.0 & 46 & 58 & 4.2 & 9.4 & 24.3 & 74.6 \\
\hline PFC4 & 27.4 & 32 & 45 & 4.1 & 8.1 & 22.8 & 69.5 \\
\hline PFC3F* & 27.1 & 47 & 60 & 4.0 & 9.3 & 23.8 & 73.9 \\
\hline
\end{tabular}

* Prepared by adding 0.3 wt.\% of polypropylene fiber (based on the sum of phosphorous slag and fly ash). moisture cured for 1 day at $20( \pm 1)^{\circ} \mathrm{C}$ and $95( \pm 2) \%$ relative humidity $(\mathrm{RH})$ in a curing chamber. Then the specimens were demolded and cured in water at $20( \pm 1)^{\circ} \mathrm{C}$ for 2 days. The original lengths were measured at the age of 3 days when the specimens were taken out of the water. The specimens were then continued to be cured in the same condition for 6 days, and the moisture curing shrinkages were measured after 3, 5 and 7 days, respectively. After that, the specimens were cured at $20( \pm 2)^{\circ} \mathrm{C}$ and $\mathrm{RH}=60( \pm 3) \%$ in a drying test chamber. The drying shrinkages from 1 day up to 49 days were measured.

\section{Cracking prevention test}

The cracking prevention effect of polypropylene fiber for AA-PS-C was tested according to the mortar plate method of CECS 38: 2004 [22]. The dosage of the fiber was $0.3 \%$ of the weight of the cement, and the test was conducted at $20( \pm 2)^{\circ} \mathrm{C}$ with $\mathrm{RH}=55( \pm 3) \%$ and the wind speed $0.5 \mathrm{~m}^{2} \cdot \mathrm{s}^{-1}$. The widths of the cracks were measured by a reading microscope with a magnification of 20 , combined with a digital camera.

\section{RESULT AND DISCUSSION}

Setting time and mortar strength

Shown in Table 3 are the results from the normal water requirement, setting time and strength tests. When the replacing quantity of fly ash for phosphorous slag increased (PF0-PF4), the setting time of the AA-PS$-212 \mathrm{C}$ increased. Addition of calcium oxide expansive agent (PFC1-PFC4) increased the water requirement of the cement and shortened the setting time. The reason for this fact is that the $\mathrm{Ca}^{2+}$ ions released by the hydration of $\mathrm{CaO}$ resulted in the flocculation of the water glass 
added as the alkaline activator. Since the calcium oxide expansive agent used in the present work was "deadburnt", the hydration activity was relatively low. In addition, the particle surface of the expansive agent was coated with aluminum stearate, which blocked the contact of particles with water, and retarded the hydration of $\mathrm{CaO}$, so that the setting accelerating effect of the calcium oxide expansive agent was greatly reduced. Alkali-activated cement with an initial setting time longer than 45 minutes was prepared when the dosage of the calcium oxide expansive agent was not higher than $3 \%$ of the sum of phosphorous slag and fly ash. When the dosage was higher, the setting time of the cement decreased to be shorter than 45 minutes.

The compressive strengths of pure AA-PS-C are very high after both 3 days and 28 days, while the flexural strengths are relatively lower. When fly ash was added as a replacement of the phosphorous slag, the compressive strength was significantly reduced, and the flexural strength after 3 days was also somewhat reduced, while the flexural strength after 28 days was increased when the replacement did not exceed $15 \%$. Since the activity of fly ash is lower than that of phosphorous slag, replacing phosphorous slag with fly ash decreased the cementitious hydration products formed after comparable times, which resulted in a decrease of compressive strength. On the other hand, the fine particles of quartz and mullite in the fly ash can play the role of a "micro-aggregate", which can, in a certain extent, block the expansion of cracks when the specimen was subjected to flexural load, and thus increase the flexural strength.

As the dosage of calcium oxide expansive agent increased, the strength of the cement decreased, though the decrement was not very significant when the dosage was not higher than $3 \%$. Adding $0.3 \%$ polypropylene fiber based on the sum of phosphorous slag and fly (PFC3F) slightly decreased the 3-day strengths, while having little effect on the 28-day strengths.

\section{Shrinkage of mortar}

Figure 1a illustrates the change of shrinkage of the AA-PS-C mortars with the replacement of phosphorous slag by fly ash at different ages. The result for PII cement mortar is also shown in the figure as a reference. During the first 7-day moisture curing, the PII cement mortar nearly did not shrink, while almost all the alkali-activated slag cement mortars shrunk in different extents. During the dry curing stage, all the specimens shrunk significantly, and the AA-PS-C mortars shrunk much more than the PII cement mortar. The greatest total shrinkage after 56 days was as high as $0.21 \%$ for PF0 mortar, $70 \%$ higher that of the PII cement mortar. When phosphorous slag was partly replaced by fly ash, the shrinkage at each age was reduced, the total shrinkages after 56 days for PF2 and PF3 with the replacement of 15 and $20 \%$, respectively, were reduced to be about $0.17 \%$. The shrinkage reduction effect of fly ash is ascribed to the low reactivity of fly ash compared with phosphorous slag powder, and the restricting effect of the inactive mineral and glassy particles in the fly ash.

Figure $1 \mathrm{~b}$ shows the change of shrinkage of the AA-PS-C mortar specimens with the dosage of calcium oxide expansive agent at different conditions and different ages. The results for the PII cement and the pure AA-PS-C (PF0) are also shown for reference. In the first 7-day moist curing, the specimens to which calcium oxide expansive agent was added not only did not shrink, but even expanded. The expansion of the cement was caused by the fact the aluminum stearate coating on the surface of the calcium oxide expansive agent particles gradually dissolved in the alkaline solution of the cement, so that the block between the water and the calcium oxide expansive agent particles was removed. The latter reacted with water and calcium hydroxide formed, resulting in an increase of the solid volume,

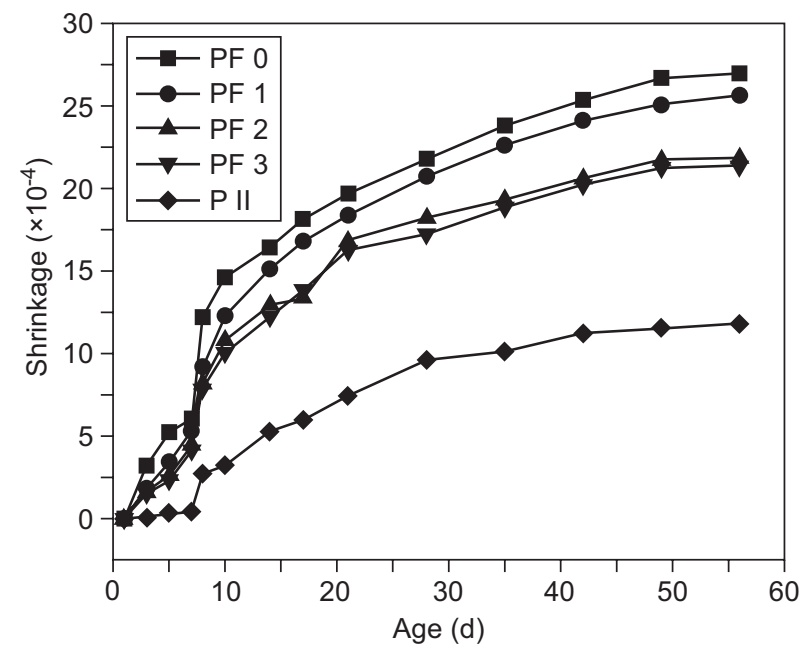

a)

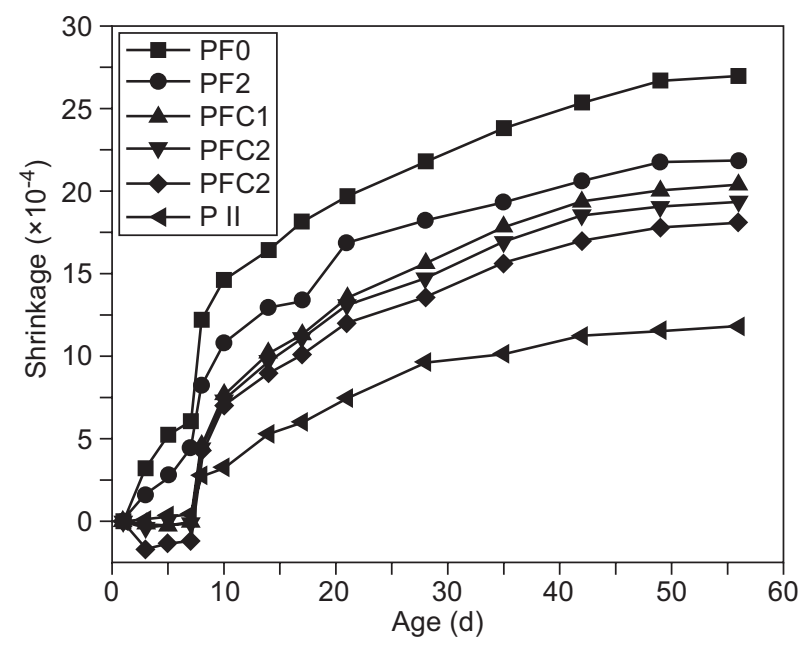

b)

Figure 1. Shrinkage vs. age for mortar specimens; a) with different fly ash replacement, b) with different dosage of calcium oxide expansive agent. 
which not only compensated the chemical shrinkage of the cement, but even caused a expansion. As the dosage of the calcium oxide expansive agent increased, the expansion of the mortars in the moist curing stage increased, while the shrinkage in the dry curing stage

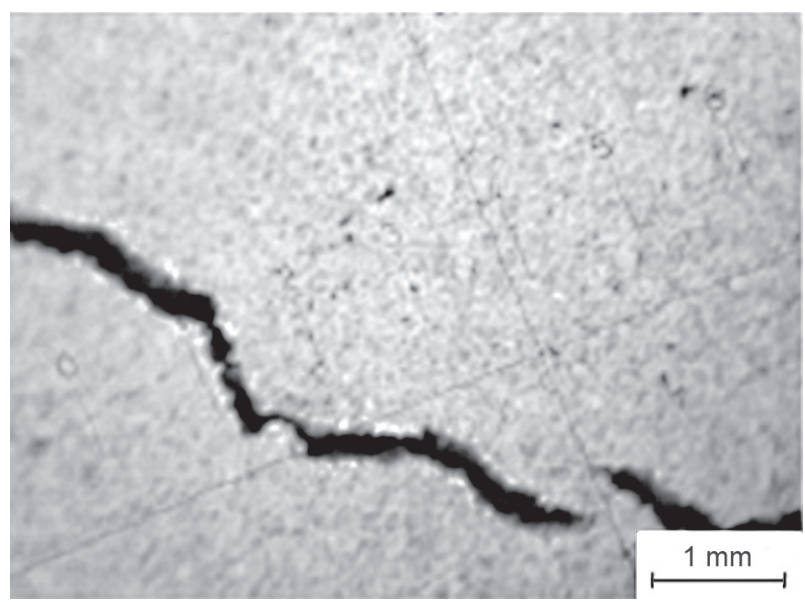

a) PF0

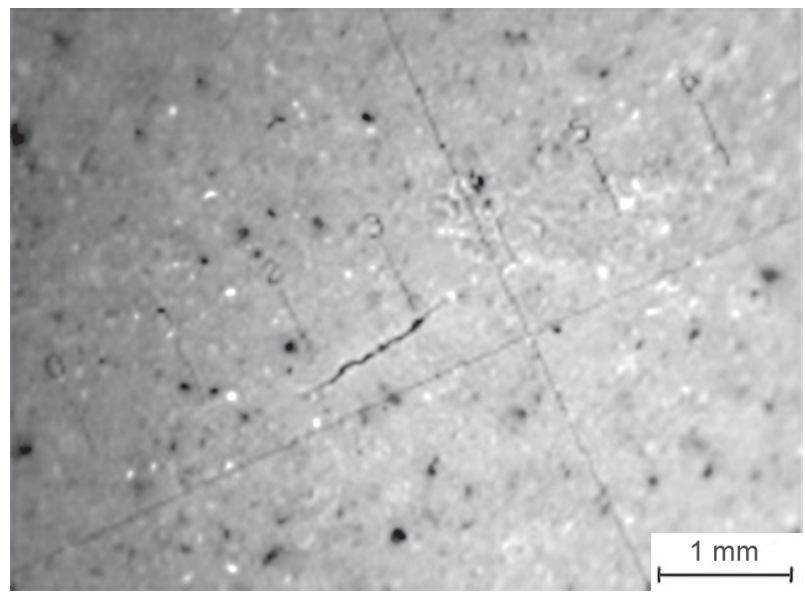

b) $\mathrm{PFC} 3$

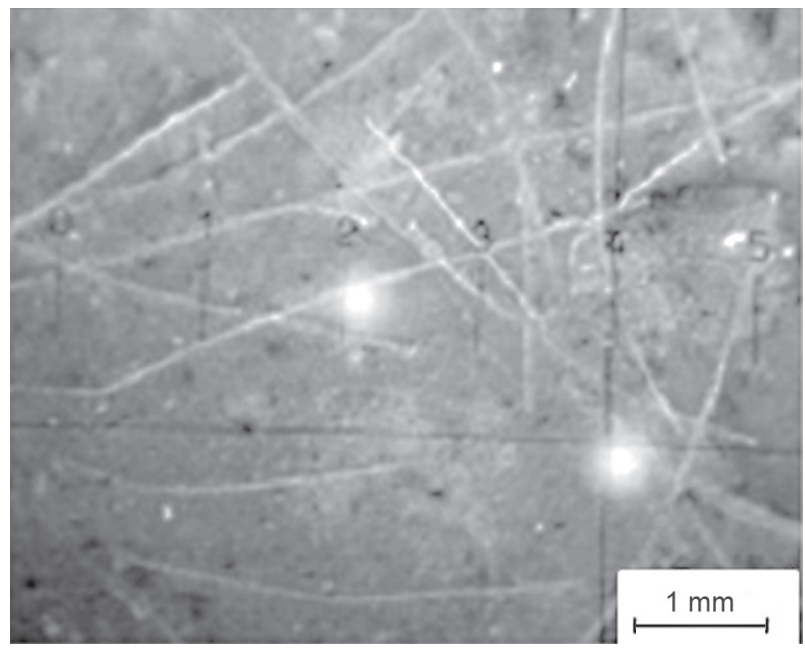

c) $\mathrm{PFC} 3 \mathrm{~F}$

Figure 2. Cracking behavior of the mortar specimens; a) PF0, b) $\mathrm{PFC} 3, \mathrm{c}) \mathrm{PFC} 3 \mathrm{~F}$. remained almost unchanged. The total shrinkage of the PFC3 mortar specimen with $15 \%$ fly ash replacement and $3 \%$ calcium oxide expansive agent dosage after 56 days was $0.12 \%$, being reduced by $40 \%$ compared with that of PF0 with neither fly ash replacement nor calcium oxide expansive agent addition. The result confirms the desirable shrinkage reducing effect of the combination of fly ash and calcium oxide expansive agent.

\section{Cracking prevention effect of polypropylene fiber}

The shrinkage of cement-based materials results in stress. Cracking will take place when the stress exceeds the tensile strength of the materials. Alkali-activated slag cement is characterized by high shrinkage, so that its shrinkage reduction and cracking prevention demands more attention. Adding fibers, especially together with expansive agent, has turned out to be efficient in preventing cracking of ordinary cement concrete.

Figures $2 \mathrm{a}, 2 \mathrm{~b}$ and $2 \mathrm{c}$ show the micrographs of the specimen surfaces, showing the cracking states of the plate mortar specimens of PF2, PFC3 and PFC3F, respectively, after 48 hours wind drying. $\mathrm{PFC} 3 \mathrm{~F}$ was prepared by adding 0.3 wt. \% polypropylene fiber to PFC3. There are quite a few cracks with lengths of 5-20 mm and widths of $0.2-0.8 \mathrm{~mm}$ on the surface of the PF2 specimen (Figure 2a). When calcium oxide expansive agent was added, the cracking was greatly reduced, and both the number and the size of the cracks of the PFC3 are much smaller than those of the PF2 specimen (Figure 2b). It is the formation of calcium hydroxide that partly compensated the chemical and drying shrinkage of the cementitious materials. When both calcium oxide expansive agent and polypropylene fiber were added (PFC3F), only very few small cracks were observed in the specimen, and no significant change took place after 72 hours wind drying. The result indicates that the crack resistance of the alkali-activated cement has been greatly improved. The cracking restriction effect of the polypropylene fiber on the alkali-activated slag cement is based on the same mechanism as that in ordinary Portland cement-based materials [13].

\section{CONCLUSIONS}

- Replacing 15 - $20 \%$ phosphorous slag by fly ash can increase the flexural strength and reduce the shrinkage of AA-PS-C.

- The calcium oxide expansive agent coated with aluminum stearate will slightly shorten the setting time and reduce the strength of AA-PS-C, but can greatly reduce the early age shrinkage.

- The combination of calcium oxide expansive agent and polypropylene fiber can greatly improve the crack resistance of AA-PS-C. 
Acknowledgements

The authors would like to gratefully appreciate financial support from the National Natural Science Foundation of China (Grant No. 51461135001 and 51139001), and the Provincial Foundation for IndustryUniversity-Research JointInnovation Cooperation(Grant No. BY2014002-04) of Jiangsu, China.

\section{REFERENCES}

1. Fang Y. -H., Mao Z. -J., Wang C. (2007): Performance of alkali-activated phosphor slag-fly ash cement and the microstructure of its hardened paste (in Chinese). Journal of the Chinese Ceramic Society, 35(4), 451-455.

2. Cheng L., Zhu C. -G., Sheng G. -H. (2006): Mechanical properties and microstructures of alkali-activated phosphorous slag cement, Journal of the Chinese Ceramic Society, 34, 604-609. doi: 10.14062/j.issn.0454-5648.2006.05.019

3. Cheng L., Sheng G. -H., Zhu C. -G. (2004): Influence of phosphorous slag on the setting time of portland cement and its mechanism analysis. Journal of Nanjing University of Science and Technology, 26(5), 5-8.

4. Douglas E., Bilodeau A., Malhotra V. M. (1992): Properties and durability of alkali-activated slag concrete. ACI Materials Journal, 89(5), 509-516.

5. Collins F.G., Sanjayan J.G. (1999): Workability and mechanical properties of alkali activated slag concrete. Cement and Concrete Research, 29(3), 455-458. doi:10.1016/ S0008-8846(98)00236-1

6. Melo Neto A.A., Cincotto M.A., Repette W. (2008). Drying and autogenous shrinkage of pastes and mortars with activated slag cement. Cement and Concrete Research, 38(4), 565-574. doi:10.1016/j.cemconres.2007.11.002

7. Gu Y.M., Fang Y.H. (2012): Shrinkage, Cracking, Shrinkage-Reducing and Toughening of Alkali-Activated Slag Cement-A Short Review. Journal of the Chinese Ceramic Society, 40(1), 76-84.

8. Atiş C.D., Bilim C., Çelik Ö., Karahan O. (2009): Influence of activator on the strength and drying shrinkage of alkaliactivated slag mortar. Construction and building materials, 23(1), 548-555. doi:10.1016/j.conbuildmat.2007.10.011

9. Folliard K.J., Berke N.S. (1997): Properties of high-performance concrete containing shrinkage-reducing admixture. Cement and Concrete Research, 27(9), 1357-1364. doi:10.1016/S0008-8846(97)00135-X

10. Collepardi M., Borsoi A., Collepardi S., Olagot J.J.O., Troli R. (2005): Effects of shrinkage reducing admixture in shrinkage compensating concrete under non-wet curing conditions. Cement and Concrete Composites, 27(6), 704-708. doi:10.1016/j.cemconcomp.2004.09.020

11. Mora-Ruacho J., Gettu R., Aguado A. (2009): Influence of shrinkage-reducing admixtures on the reduction of plastic shrinkage cracking in concrete. Cement and Concrete Research, 39(3), 141-146. doi:10.1016/j.cemconres. 2008.11.011

12. Palacios M., Puertas F. (2004 (2007): Effect of shrinkagereducing admixtures on the properties of alkali-activated slag mortars and pastes. Cement and Concrete Research, 37(5), 691-702. doi:10.1016/j.cemconres.2006.11.021

13. Song P.S., Hwang S., Sheu B.C. (2005): Strength properties of nylon-and polypropylene-fiber-reinforced concretes. Cement and Concrete Research, 35(8), 1546-1550. doi: 10.1016/j.cemconres.2004.06.033

14. Padron I., Zollo R. F. (1990) : Effect of synthetic fibers on volume stability and cracking of portland cement concrete and mortar. ACI Materials Journal, 87(4), 327-332.

15. Bayasi Z., Mclntyre M. (2002): Application of fibrillated polypropylene fibers for restraint of plastic shrinkage cracking in silica fume concrete. ACI Materials Journal, 99(4), 337-344.

16. Bayasi Z., Zeng J. (1993): Properties of polypropylene fiber reinforced concrete. ACI Materials Journal, 90, 605-605.

17. China National Development and Reform Commission (NDRC of China): JC/T 1088-2008 Method for chemical analysis of granulated electric furnace phosphorous slag, 2008-06-16.

18. China General Administration of Quality Supervision, Inspection and Quarantine (GAQSIQ of China), and China National Standardization Management Committee (NSMC of China): GB/T 176-2008 Method for chemical analysis of cement, 2008-06-30.

19. China General Administration of Quality Supervision, Inspection and Quarantine (GAQSIQ of China), and China National Standardization Management Committee (NSMC of China): GB 175-2007 Common Portland cement, 2007-11-09.

20. China General Administration of Quality Supervision, Inspection and Quarantine (GAQSIQ of China), and China National Standardization Management Committee (NSMC of China): GB/1346-2001 Test methods for water requirement of normal consistency, setting time and soundness of the Portland cement, 2011-07-20.

21. China State Bureau of Quality and Technical Supervision (SBQTS of China): GB/T17671-1999 idt ISO 679:1989 Method of testing cements-Determation of strength, 1999-02-08.

22. Standardization Institute of Chinese Construction: CECS 38:2004 Technical specification for fiber reinforced concrete structure, 2004-11-01 